\title{
ambient SCIENCE

\section{The Relationship between the Opium Drug and the Risk of Laryngeal Squamous Cell Cancer}

\section{Nezameddin Berjis, Mehrdad Rogha, Mehdi Shahabeddini*}

Department of Otorhinolaryngology, School of Medicine, Isfahan University of Medical Sciences, Isfahan, Iran

Study Area: Isfahan, Iran

Coordinates: $32^{\circ} 38^{\prime} \mathrm{N} ; 51^{\circ} 39^{\prime} \mathrm{E}$

Keywords:Smoking, Alcoholic, Drug addict

\section{Introduction:}

Squamous cell cancer of the larynx is the most common malignant neoplasm of the larynx which includes in $85 \%$ to $95 \%$ of larynx cancer cases (Jemal et al.., 2007).The goal of the treatment of laryngeal cancer is must be of complete removal and treatment of the disease (Jemal et al., 2007; Barnes et al., 2005; Armstrong \& Netterville, 1995). The male to female ratio was reported to be 3.8 to 1 (Jemal et al., 2007). Cancers such as laryngeal cancer are strongly influenced by environmental factors but, the genetic susceptibility including detoxification enzymes polymorphism phase 1 and 2 and polymorphism of repair DNA enzymes also are influence the same. Diet including vegetables, fruits and reduced consumption of meat and fat reduces the risk of head and neck cancers, such as cancers of the colon and cardiovascular (Meyskens \& Szabo, 2005; Gonzalez, 2006). Among the risk factors for Squamous cell cancer of larynx cigarettes, alcohol, reflux laryngopharyngeal (Ward \& Hanson, 1988; Morrison, 1988), human papillomavirus (Halec et al.., 2013) and cytotoxic (asbestos, solvents, organic, sulfuric acid, sulfur mustard gas, oils Mineral particular, dust, metals, wood dust, asphalt, stone, fiberglass and cement dust) can be the most resposible (Maier et al.., 1992; Wight et al..,

\section{Abstract}

Smoking and alcoholism are listed as the factors related to laryngeal squamous cell cancer malignancies. Some experiences have acknowledged the high prevalence of addiction in this type of cancer. Keeping in mind the same, this study aimed to determine the association between the opium drugs with squamous cell cancer of the larynx. In the year 2015 in Al-Zahra and Kashani Isfahan hospitals, 180 patients with laryngeal squamous cell cancer and 180 healthy controls were studied and the prevalence of risk factors ranging from smoking, alcohol and drug addiction for this type of cancer, in both groups were determined. In both groups of control and patients in respective 3.9\% Vs. $65.1 \%$ ratio were taking the drug respectively and opioid consumption was significantly higher in the patient group. Opium drug addiction is a significant risk factor in developing squamous cell carcinoma of the larynx that may even have an effect far more than cigarettes and alcohol. It also recommended further studies for drug addicts, especially opium, to study the symptoms of laryngeal cancer of the mouth in this group.

2003), among them, the most important risk factors cited in the books and articles are alcohol and tobacco (alone or combindly) severely raise the risk of laryngeal cancer (Blot et al.., 1988; Menvielle et al.., 2004). Unfortunately, except two internal studies on the relationship between opium and squamous cell laryngeal cancer (Mousavi et al.., 2003; Sobhani, 2004) till date no much work has been done on the effect of opium on laryngeal squamous cell cancer. In a report by Mousavi et al. (2003) in Mashhad University of Medical Sciences, it was noted that opium can synergistically enhance the grade of squamous cell carcinoma of the larynx and decrease the patients' age. In numerous biopsy laryngoscopy and laryngectomy done in Kashani hospital of Isfahan, a relationship between smoking and consumption of opium, along with many of laryngeal squamous cell cancer have been evidences where the association was seen less in alcohol consumption that the problem can be caused by different habitats of people for this region (Iran) as of opium drug consumption instead of alcohol than Westerners or its own carcinogenic effects of opium, either independently or in association with smoking. In this study, the use of opium as an independent risk factor or linked in combination with smoking in increasing the risk of squamous cell cancer of 
the larynx has been investigated. Due to cultural issues and the use of opium in the country, this study may help reduce the incidence of squamous cell laryngeal bring in Iran and even in the Middle East.

\section{Methodology:}

This study is a case-control study which was conducted in the educational centers of Al-Zahra and Kashani Isfahan hospitals. The subject of the study was patients with squamous cell carcinoma of the larynx who were referred to the mentioned centers and underwent biopsy laryngoscopy and confirmed the diagnosis of laryngeal cancer SCC in between the year 2014-2015. Also for control group over 40 persons with no laryngeal cancer but referred to Kashani and Al-Zahra hospitals of Isfahan and who fully cooperated in completing the questionnaire were selected. Inclusion criteria consisted of laryngeal squamous cell carcinoma biopsy proven by two pathologists, availability of information in patient records, and the possibility of contact with the patient or his family to complete data, lack of family history of cancer and squamous cell carcinoma of head and neck and other masses except the squamous cell cancer of the larynx. Also failure to complete due to lack of cooperation from the patient or his family or lack of address and telephone number to provide information and modify data was considered as exclusion criteria. The sample size requirement in this study was calculated using sample size formula to compare proportions and taking into account the $95 \%$ confidence level and statistical power of $80 \%$ prevalence of substance use in patients with squamous cell cancer of the larynx due to the lack of similar studies were considered 0.5 and least significant difference between the two groups was considered to 0.15 a number of 174 patients in each group was estimated that the 180 patients in each group were studied for more confidence. After approval of the proposal and coordination, visiting researcher at the medical records unit, firstly the list of patients with a diagnosis of squamous cell cancer of the larynx who have been operated during 2014 and 1015, priority has been prepared with more new cases by reviewing patient records and public demographic information including gender, age, smoking, drug and alcohol use and family history of laryngeal squamous cell cancer which were recorded in data record forms. If there are defects in the case information, contact was made to the patient or his family to complete data and if the patient's family refuses to respond, patients were excluded from the study. The control group was made of people over 40 years of nonsquamous cell cancer of the larynx and referred to the clinics of Kashani and Al-Zahra hospitals and had adequate cooperation and questionnaires were completed for them. These people were under indirect laryngoscopy examination and if there is any type of laryngeal lesions were excluded from the study. Data were analyzed with
SPSS version 23 and descriptive results were done using charts, graphs and central and dispersion parameters and results were analyzed using chi-square t-test and logistic regression test.

\section{Results:}

In this study, 180 patients with squamous cell carcinoma of larynx cancer and 18o healthy controls were considered. The mean age of the patients and the control groups were $59.5 \pm 10.9$ and $58.4 \pm 10.2$ years respectively with no statistically significant difference $(\mathrm{p}<0.35)$. Based on the results, less than $20 \%$ of patients $(18.3 \%)$ were under 50 years of age and $15 \%$ of them were aged 70 years and above, and thus, more than 60 percent of disease etiology (66.7\%) were in the age group 50-6o years. In both the patient and control groups, 178 were male and two were female ( $98.9 \%$ Vs 1.1\%; Fig.-1).

In Table-1, the frequency of smoking, alcohol and drug user in patients and controls are shown. As per the results, 55 patients from the control group and 157 cases of patients were smokers (30.6\% Vs. 87.2\%) and the smoking percentage was higher is a patients group and difference was significant $(\mathrm{P}<\mathrm{0.001})$. Further, the use of drugs in control and patient groups were 7 and 101 people $(3.9 \%$ Vs. $65.1 \%$ ) respectively and opioid consumption was significantly higher in patients group $(\mathrm{P}<0.001)$. In terms of alcohol consumption, 2 and 8 of control and patient groups respectively (1.1\% Vs. $4.4 \%$ ) consumed alcohol and in accordance with the test, alcohol consumption were not signif icantly different between the two groups $(\mathrm{p}<0.1)$.

Logistic regression test conducted on the data revealed that the two variables have a signif icant effect on scc cancer of the larynx which were opium and smoking so that smoking increases the risk of SCC cancer of the larynx equal to the amount of 8.8 (confidence interval 4.8-16) that this increase was statistically signif icant $(\mathrm{p}<0.001)$, as well as the chances of getting cancer with drug consumption that has been increased at a rate equal to 18.6 (confidence interval 7.9-43.6) which was statistically significant $(\mathrm{p}<0.001)$. But other variables, such as alcohol consumption, age, and sex had no significant effect on increasing the risk of SCC cancer of the larynx.

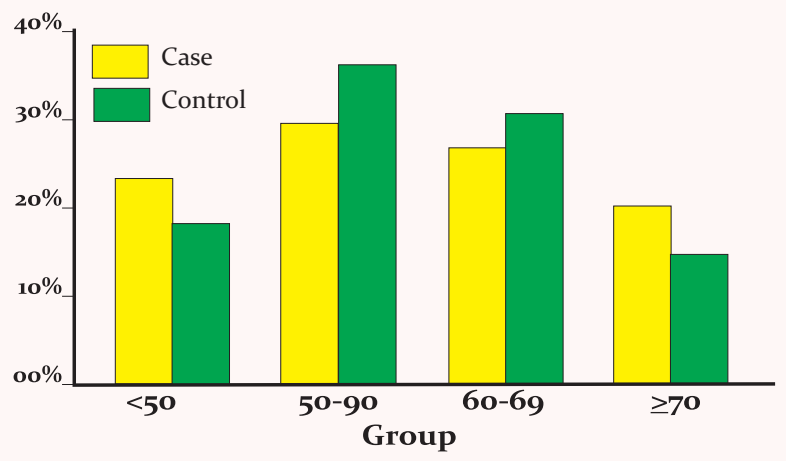

Figure-1: Frequency percentage of age groups in the case and control groups 
Table-1: Frequency distribution of smoking, alcohol consumption and drug addiction in the two groups

\begin{tabular}{llll}
\hline Variables & Control & Case & $P$ (value) \\
\hline Smokers & $55 / 30.6 \%$ & $157 / 87.2 \%$ & $<0.001$ \\
Drug Addicted & $7 / 3.9 \%$ & $101 / 56.1 \%$ & $<0.001$ \\
Alcoholic & $\mathbf{2} / 1.1 \%$ & $8 / 4.4 \%$ & $<0.1$ \\
\hline
\end{tabular}

Discussion:

Laryngeal squamous cell cancer is of malignancies that can be treated by laryngectomy and Chemoradiation. The major risk factors for this disease can be the involvement of a person in smoking and alcoholism. In many laryngectomies which were performed in Isfahan Kashani and Al-Zahra hospitals, patients were seen to be dependent on Opium. On the other hand, in the recent years, an increase in drug addiction and the incidence of laryngeal cancer at the same time is seen to be increasing; therefore, this study has an importance to shed some light on the relationship between drug addiction and cancer. Based on the results, the prevalence of smoking and drugs in patients with SCC cancer of the larynx was signif icantly higher than the control group and the risk of laryngeal cancer in smoking and drug groups were $8.8 \%$ and $18.6 \%$ respectively and though the results may be somewhat exaggerated but anyway smoking as one of the major risk factors for squamous cell cancer of the larynx area is considered and on the other hand, some other studies have been reported the relationship between the incidence of this type of cancer and addiction to drugs, particularly opium. Earlier Sobhani (2003) conducted a study on 75 patients with laryngeal cancer and 305 normal subjects and the prevalence of smoking in the patient group was $92 \%$ and $80 \%$ of them were addicted to opium. In this study, the risk of squamous cell carcinoma of the larynx for cigarettes was 18 and 24 have been obtained for the drug. In another study, Mousavi et al. (2003), 98 patients with laryngeal squamous cell cancer and 312 healthy people were compared in term of addiction to opium and the prevalence of opium addiction in the two groups of patients and control subjects were $13.3 \%$ and $76.5 \%$, and the difference was signif icant. So we can say that drugs are an important risk factor in the development of laryngeal cancer, although other factors such as smoking and alcohol are also involved. Based on our results, $98.9 \%$ of patients with laryngeal squamous cell carcinoma were male and $1.1 \%$ were female, that compared to other studies this ratio was higher. According to available literature, the ratio of male to female was four to one (Greene et al., 2002). In terms of age distribution, the highest number of patients was in the age range of 50-6o years. So that the incidence of this cancer was in the age range of 60-50 years, 66.7 percent, but in our study, the effect of age and gender were not observed in the incidence of laryngeal squamous cell carcinoma.
The limitations of our report is that the study was retrospective and data from the patients were obtained from the records, available with the respective hospital or through telephonic questionnaires. Therefore, it was not possible to determine the exact rate and duration of opium consumption, so the relationship of laryngeal cancer with rate and duration of opium consumption was not evaluated.

\section{Conclusions:}

Our study alongwith some other studies revealed that the addiction to drugs, particularly opium, is a signif icant risk factor in developing squamous cell carcinoma of the larynx that may even have an effect far more than cigarettes and alcohol. Thus it is recommended that the drugs addicts persons, especially of opium, must be examined periodically in terms of the symptoms of mouth cancer, especially of the larynx. These people must be sensitive to the warning signs, such as hoarseness, dysphagia, odynophagia or other laryngeal symptoms and upper respiratory tract that to face and immediately undergo ear, nose, and throat careful examination and diagnostic and therapeutic process.

\section{Acknowledgment:}

The present study is a dissertation to receive a Ph.D. in the field of ear, nose and throat that was approved as 394211 in medical school research department and was carried out with the support of this department. Therefore, the authors are appreciated of their efforts.

\section{References:}

Armstrong, W.B. \& Netterville, J.L. (1995): Anatomy of the larynx, trachea, and bronchi. Otolaryngol. Clin. North Am., 28(4):685-699.

Barnes, L., Tse, L.Y., Hunt, J.L., Brandwein-Gensler, M., Urken, M., Slootweg, P., Gale, N., Cardesa, A., Zidar, N. \& Boffetta, P. (2005): Tumours of the hypopharynx, larynx and trachea: introduction, pp.111-117. In: Barnes L, Eveson J, Reichart P, Sidransky D, ed. World Health Organization Classification of Tumours. Pathology and Genetics of Head and Neck Tumours, Pub. by: Lyon: IARC Press.

Blot, W.J., McLaughlin, J.K., Winn, D.M., Austin, D.F., Greenberg, R.S., Preston-Martin, S., Bernstein, L., Schoenberg, J.B., Stemhagen, A. \& Fraumeni, J.F. Jr.. (1988): Smoking and drinking in relation to oral and pharyngeal cancer. Cancer Res., 48(11):3282-3287.

Gonzalez, C.A. (2006): The European Prospective Investigation into Cancer and Nutrition (EPIC). Public Health Nutr., 9(1A):124-126.

Greene, F.L., Page, D.L., Fleming, I.D., Fritz, A.G., Balch, C.M., Haller, D.G. \& Morrow, M. (2002): AJCC cancer staging manual. 6thed. Pub. by: New York, Springer, 9. 421.

Halec, G., Holzinger, D., Schmitt, M., Flechtenmacher, C., Dyckhoff, G., Lloveras, B., Höfler, D., Bosch, F.X. \& Pawlita1, M. (2013): Biological evidence for a causal role of HPV16 in a small fraction of laryngeal squamous cell carcinoma. $\underline{B r}$.$] .$ 


\section{TECHNOSCIENCE ARTICLE}

Cancer, 109(1):172-183.

Jemal, A., Siegel, R., Ward, E., Murray, T., Xu, J. \& Thun, M.J.(2007): Cancer statistics, 2007. CA Cancer J. Clin., 57(1):43-66.

Maier, H., Gewelke, U., Dietz, A. \& Heller, W-D. (1992): Risk factors of cancer of the larynx: results of the Heidelberg case-control study. Otolaryngol. Head Neck Surg., 107(4):577-582

Menvielle, G., Luce, D., Goldberg, P., Bugel, I. \& Leclerc, A. (2004): Smoking, alcohol drinking and cancer risk for various sites of the larynx and hypopharynx: a case-control study in France. Eur. J. Cancer Prev., 13(3):165-172.

Meyskens, Jr. F.L. \& Szabo, E. (2005): Diet and cancer: the disconnect between epidemiology and randomized clinical trials. Cancer Epidemiol. Biomarkers Prev., 14(6):1366-1369.
Ambient Science, 2018: Vol. 05(Sp1); 16-19 DOI:10.21276/ambi.2018.05.sp1.ta01

Mousavi, M.R., Damghani, M.A., Haghdoust, A.A. \& Khamesipour, A. (2003): Opium and Risk of Laryngeal Cancer. Laryngoscope., 113(11):1939-43.

Sobhani, S. (2004): Prevalence of opium abuse among patients with laryngeal cancer. MD Thesis of Kerman University of medical Sciences, Iran.

Ward, P.H. \& Hanson, D.G. (1988): Reflux as an etiological factor of carcinoma of the laryngopharynx. Laryngoscope, 98(11):1195-1199.

Wight, R., Paleri, V. \& Arullendran, P. (2003): Current theories for the development of nonsmoking and nondrinking laryngeal carcinoma. Curr. Opin. Otolaryngol. Head Neck Surg., $11(2): 73-77$.

Morrison, M.D. (1988): Is chronic gastroesophageal reflux a causative factor in glottic carcinoma? Otolaryngol. Head NeckSurg., 99:370-373.

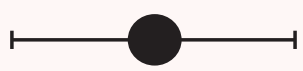

